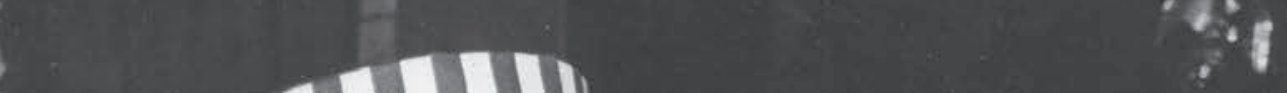

|| || || |||
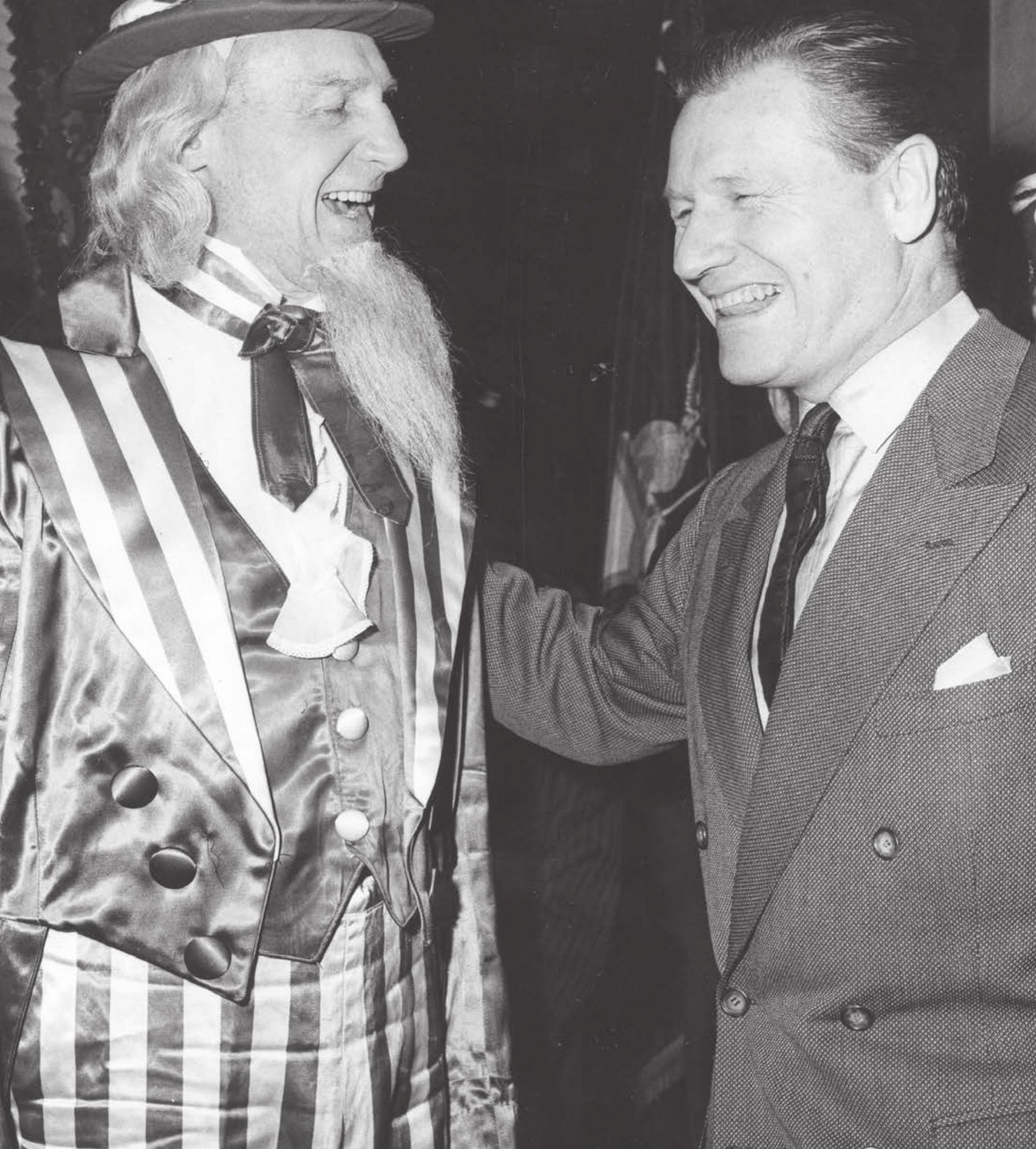


\section{Serge Guilbaut}

\section{Respingos na parada modernista: a invasão fracassada da arte abstrata no Brasil, 1947-1948}

Drips in the modernist parade:

The failed invasion of abstract art in Brazil, 1947-1948

\begin{abstract}
palavras-chave: modernismo; arte moderna; museus de arte moderna; abstração; política internacional; Léon

Degand
\end{abstract}

keywords: modernism; modern art: museums of modern art; abstract art; international politics; Léon

Degand
Tendo como pano de fundo não apenas os acontecimentos mas também os discursos que cercaram a criação do primeiro museu de arte moderna no Brasil, este ensaio pretende analisar as possíveis conexões da formação de um acervo de arte atento às ideias de "moderno" e de "abstrato" com a emergência de uma sociedade urbana no país e com certos interesses de política internacional durante a Guerra Fria.

With the backdrop of not only the events but also the rhetoric that surrounded the creation of the first museum of modern art in Brazil, this essay aims to examine possible connections of the formation of an art collection observant of the ideas of "modern" and "abstract" with the emergence of an urban society in the country and certain interests of international politics during the Cold War. 
"Aqui importa-se tudo. Leis, ideias, filosofias, teorias, assuntos, estéticas, ciências, estilo, indústrias, modas, maneiras, pilhérias, tudo vem em caixotes pelo paquete. A civilização custa-nos caríssimo, com os direitos de Alfândega: e é em segunda mão, não foi feita para nós, fica-nos curta nas mangas..."

(João da Ega em Os Maias, de Eça de Queirós).
1. Ver BRETON, André. Arcane 17. Nova lorque: Brentano, 1944.
Entre os anos de 1946 e 1948, duas cargas importantes para esta história cruzaram o atlântico. Uma, a caminho da França, levava as doações de André Breton que consistiam em artefatos de indígenas da costa noroeste da América; a outra, deixando a costa oeste francesa com uma carga de pinturas abstratas modernas reunidas pelo crítico de arte belga Léon Degand, dirigia-se ao Brasil para criar o Museu de Arte Moderna de São Paulo. Esses cruzamentos históricos virtuais marcam na imaginação a viagem através do Atlântico de dois grupos de ideias antagônicas sobre o que constitui a arte - ideias antagônicas, mas que eram semelhantes no sonho que ambas sintetizavam. Esses cruzamentos, viagens e deslocamentos deveriam, por um lado, renovar um sistema visual ocidental antigo e desgastado com a entrada de elementos revigorantes trazidos do Novo Mundo, por outro, encontrar um espaço mais hospitaleiro (o que naquele momento era necessário) para o desenvolvimento da mais nova expressão de modernidade.

Em 1946, André Breton deixou o exílio em Nova Iorque, onde passou os tempos de guerra, para voltar a Paris, onde esperava continuar a sua luta política e estética pela libertação do pensamento. No entanto, Breton não apenas levava consigo uma nova maneira de pensar e um novo conjunto de teorias, incluindo a reavaliação das culturas "primitivas" que encontrara na América do Norte - refiro-me ao seu interesse, seguindo Friedrich Engels, em recuperar o conceito aborígine de matriarcado como substituto ao sistema patriarcal ocidental falido e destrutivo ${ }^{1}$ - estava também transportando contêineres repletos de artefatos, esculturas, máscaras e construções das culturas da costa noroeste e sudoeste da América do Norte. No pensamento subversivo de Breton, esses objetos, antes invisíveis, poderiam atuar como uma nova invasão libertária na psique francesa. Sua descoberta teria um papel importante, pensava ele, na reconstrução da alma francesa, corrompida por tantos anos de imperialismo e fascismo. Esses complexos objetos eram para ele como uma poderosa "revanche dos primitivos" capaz de fornecer novas armas estéticas e simbólicas à esquerda francesa no intuito de promover a guerra contra a sempre presente e desprezível burguesia. A volta daqueles que foram por muito tempo oprimidos ou reprimidos era entendida como 
uma arma contra uma cultura francesa ainda atrelada a estereótipos cartesianos e coloniais. Breton estava literalmente carregando a renovação espiritual em suas malas. Essa viagem de cura que atravessava o oceano da América para a Europa, esse deslocamento de objetos estéticos de um continente para o outro, foi semelhante à travessia do Atlântico feita por Léon Degand, mas ao contrário.

O critico de arte belga que havia trabalhado em Paris embarcou para o Brasil em 1947 levando consigo diversos caixotes repletos de pinturas modernas feitas em Paris - na sua maioria abstrações geométricas - para introduzir uma forma de arte abstrata especificamente otimista no novo continente e para disseminar uma nova linguagem contemporânea em um país de rápido crescimento no processo de modernização.

Se Breton estava tentando ensinar à Europa sobre a loucura das ideias reacionárias do passado através de produções estéticas nativas do novo continente, León Degand tentava trazer, de forma involuntariamente irônica, o "moderno" do velho ao novo mundo. Essa é uma história de utopia, ingenuidade e arrogância, mas também uma história de equívocos e de resistência, de hegemonia e orgulho, dos frios parâmetros ortogonais modernistas, incapazes de controlar a vitalidade, e a resistência da exuberância e da diferença tropical: tudo isto inscrito na complexa construção das histórias pessoais de Léon Degand e seu círculo. Essa é a fábula labiríntica de uma batalha de clichês em torno de um menage à trois envolvendo Paris, São Paulo e Nova Iorque, cidades apaixonadas pela arte moderna.

Essa história, recorrendo ao ditado de Lautreamont, fala do encontro casual de um rico empreendedor brasileiro de descendência italiana chamado Francisco Matarazzo, amante da arte contemporânea, e um crítico belga que trabalhava em Paris, especialista em abstração, na mesa de um café de Paris em 1947. Tal encontro pode parecer bastante inócuo, ou até mesmo surrealista, já que essa pausa para o café estava carregada de ansiedade, medo e instabilidade. Daquele terraço, enquanto a capital francesa era dominada por uma série de greves terríveis orquestradas por um Partido Comunista extremamente combativo, o mundo parecia estar rapidamente se desintegrando em uma Guerra Fria. Por trás da inocência de se organizar uma exposição tomando um cafezinho, agigantava-se um mundo inteiro de intrigas de guerra fria, armações políticas e ações encobertas. Mas sobre o quê então se tratava esse encontro? O que estava fazendo em Paris esse riquíssimo brasileiro, proprietário de uma série de fábricas por todo o Brasil, aparentemente por trás de $75 \%$ do total dos negócios de conservas na América do Sul, ao tomar café com um crítico de arte modernista, Léon Degand? Em que tipo de negócios ele andava envolvido lá e por qual razão? E, do mesmo modo, por que um crítico 
conhecido estava escrevendo para o jornal cultural de esquerda Les Lettres Françaises, fazendo acordos com a aristocracia latino-americana com tanta antecipação? A resposta é complicada e envolve não apenas a política do modernismo, a sedução da abstração, o sonho de universalismo e o poder do dinheiro, mas também a batalha pela supremacia cultural de âmbito mundial na qual o Brasil e a Argentina pareciam estar entre os prêmios mais cobiçados. Tal competição tinha muitas tramas complicadas, incluindo os diversos níveis de interesse já bem conhecidos de Nova Iorque na América Latina, a competição cultural entre a França e os Estados Unidos e os conflitos pela hegemonia cultural dentro do próprio Brasil. Meu objetivo aqui não é reescrever a história da arte moderna no Brasil, mas sim investigar as ramificações e os emaranhados que cercam a criação do primeiro Museu de Arte Moderna no Brasil, especialmente à luz dos esforços do Museu de Arte Moderna em Nova Iorque de disseminar essa missão internacionalmente.

Ao fazer isso, tentarei desvendar a complexa série de conexões que permitiu que as noções de "moderno" e de "abstrato" se tornassem tão atraentes e cruciais para os interesses dos Estados Unidos e para a política internacional no início da Guerra Fria. Meu argumento é o de que a criação de tal museu em São Paulo estava no centro de uma série de discursos que tinham relação com a política internacional e com as lutas nacionais pelo poder. Tomarei a experiência de Léon Degand como o fio condutor de um experimento intenso no qual ele, sem que tivesse o controle, conseguiu desencadear uma cascata de eventos e reações que participaram na ativação das políticas da Guerra Fria. É através dessa experiência que tentarei analisar e enfatizar os sonhos de progresso e libertação alimentados pelas fantasias de Degand, juntamente com os sonhos de elegância internacional de Matarazzo e a realidade do poder interamericano acumulada nas mãos de Nelson Rockefeller no início da Guerra Fria.

\section{O MoMA descobre o Brasil}

2. Ver as quatro

fascinantes páginas do relatório de Rene d'Harnoncourt nos Arquivos da Fundação Rockefeller, datados de 9 de abril de 1945 (Coleção do MoMA, Record Group III 4L, Caixa 135, Pasta 1325).
Dois dias após o natal de 1944, Renee d'Harnoncourt deixou o Museu de Arte Moderna em Nova Iorque com a benção do Conselho de Diretores para uma viagem de informação à America Latina que durou até março de $1945^{2}$. Ele viajou à Cidade do México, Lima, Santiago, Chile, Buenos Aires, Mar del Plata, Rosário, Rio de Janeiro, São Paulo, Belém e Porto Príncipe para iniciar um campanha em busca de sócios para o museu e para investigar o mercado de venda de livros e reproduções, a recepção de exposições itinerantes e o estabelecimento de um circuito de distribuição de filmes da cinemateca do MoMA. A moderna 
imagem de uns Estados Unidos energético era vista pelo museu como crucial para a reorganização do ocidente, enquanto a guerra se encerrava em direção a um futuro ainda incerto. Por todos os lados onde Harnoncourt passava, ele recebia respostas entusiasmadas de socialites e particularmente de arquitetos e colecionadores de arte avidamente interessados nas questões modernas. Mas, ao mesmo tempo, ele rapidamente se deu conta de que a elite latino-americana já se encontrava sob a importante influência cultural das bem estabelecidas tradições francesa e britânica. Como foi descrito em um documento do Departamento de Estado, os Estados Unidos concentravam suas atenções especificamente no Brasil para a entrada da cultura moderna porque este era o único país de língua não hispânica, além de ser o único Estado que não estava envolvido em discussões e disputas interamericanas. O Brasil - este gigante da economia em potencial tornou-se então o principal alvo, o prêmio mais cobiçado de uma disputa cultural durante o período de reorganização global do ocidente. Esse remapeamento de fronteiras culturais não era somente uma via de mão única que servia apenas aos interesses americanos: a noção de modernidade era um fator definitivamente crucial para uma parte da alta sociedade e da intelectualidade brasileira.

Às vésperas de uma reorganização mundial pós Segunda Guerra Mundial, a classe empreendedora brasileira quis, como em outras sociedades ocidentais, afirmar a sua identidade progressista através do desenvolvimento de instituições culturais privadas e, em particular, como aconteceu em Nova Iorque no final da década de 1930, no âmbito da arte moderna. A historiadora de arte brasileira Aracy Amaral acompanhou e analisou o desenvolvimento progressivo dos museus modernos em São Paulo e no Rio de Janeiro e mencionou as estreitas ligações entre o Museu de Arte Moderna de Nelson Rockefeller e Sérgio Milliet, diretor da Biblioteca Municipal de São Paulo, em função do amor que ambos tinham pela cultura moderna e pela a arte. Durante todo o ano de 1946, Milliet, em correspondência com Nelson Rockefeller, descreveu detalhadamente os seus esforços para organizar uma associação que disseminasse a arte moderna e divulgasse para o público brasileiro a importância da mais recente evolução da produção artística no mundo desenvolvido. Milliet acreditava que a arte moderna era de suma importância para o desenvolvimento de uma cultura urbana e liberal no Brasil.

A arte moderna foi também crucial para essa cultura durante um momento decisivo de esforço político e social que havia revelado um Brasil entre uma tradicional sociedade rural conservadora e uma sociedade urbana progressiva. Essa dicotomia era uma construção com- 
3. Apesar do fato de o governo dos Estados Unidos não considerar

a América Latina uma área crucial, ajudou através do Export-Import Bank a construir o Complexo Siderúrgico de Volta Redonda. Mas o que também deve ser dito é que depois da guerra o governo dos Estados Unidos preferiu ficar atento à Europa ao invés da América Latina. Nelson Rockefeller e seu interesse particular eram um caso específico.

4. Ver meu artigo intitulado Post-war Painting Games: the Rough and the Slick IIn: GUILBAUT, Serge.

Reconstructing Modernism: Art in New-lorque, Paris, and Montreal, 1945-1964. Cambridge: M.I.T. Press, 1990, plexa, mas o mínimo que se pode dizer é que desde 1943 uma genuína revolução social e tecnológica estava se desenrolando com a usina siderúrgica de Volta Redonda, que foi a primeira deste tipo não apenas na América Latina, mas em todo o mundo subdesenvolvido ${ }^{3}$. Essa nova industrialização e essa mudança (durante o governo de Getúlio Vargas), particularmente em São Paulo, ofereceram uma base totalmente nova e otimista para que fosse redefinida uma identidade do país na qual a arte moderna tinha um importante papel a cumprir. Pode-se compreender agora como a fé no progresso, tradicionalmente implantada pela tradição modernista, foi importante para a nova liderança industrial em desenvolvimento, mas também como foi difícil convencer um público que se achava perdido com relação à conexão aparentemente obscura entre a modernização e a abstração artística. Em 1946, os cânones da elite estética no Brasil ainda eram o Realismo e o Impressionismo, apesar de algumas incursões feitas por uma atraente reconfiguração do modernismo por meio dos movimentos de "Antropofagia" e "Cercle et Carré”. O mais impressionante, no entanto, era a velocidade com a qual uma burguesia progressista brasileira agora abraçava as estratégias vanguardistas e a arte modernista.

Um tipo de fervor missionário estava no centro da investida na arte moderna por parte do MoMA depois da Segunda Guerra Mundial. Mas para admiti-la na cruzada pela liberdade, a arte teria de ser esvaziada de grande parte de suas tendências agressivas e subversivas. A insistência da vanguarda nas noções de individualismo e liberdade fez da "arte contemporânea", ou seja, da arte moderna, um elemento extremamente valioso na construção de um liberalismo contemporâneo em constante oposição ao comunismo. Esta é a razão pela qual o recrutamento da arte moderna pela causa liberal entrava em choque com a mitologia tradicional que envolvia o modernismo e o vanguardismo. Para que funcionasse, a arte moderna teria que ser subversiva, sacudir as certezas estabelecidas, ter condição de produzir um discurso disjuntivo esculpido a partir de posições realmente divergentes. Essa é uma das muitas razões pelas quais Picasso se recusou a apoiar Alfred Barr e o Museu de Arte Moderna em Nova Iorque em sua luta contra demagogos da esquerda que em 1948 tentavam rejeitar a arte moderna por considerá-la perigosa ${ }^{4}$. Alguns críticos de arte em Nova Iorque (poucos, até então) e o próprio MoMA, é claro, estavam envolvidos na venda da arte moderna para um público interessado que crescia lentamente. Dada a falta de educação artística e a falta de tradição modernista por parte do público dos Estados Unidos, um grande esforço foi feito pelo MoMA durante e depois da guerra para educar este público acerca dos prazeres do individualismo que se en- 
p. 30-84). Para Picasso, os inimigos da arte moderna na verdade estavam certos, pois, como ele entendia, 0 principal papel dos artistas modernos era o de se voltar contra as grandes e poderosas instituicões: ser subversivo. Seu chamado era para lutar, subverter o status quo, constantemente tentando evitar a transformação da criticidade da arte moderna em pequenos brinquedos para os ricos. Na verdade, a arte moderna, de acordo com

Picasso, não era um brinquedo, mas sim uma poderosa arma. 0 MoMA não enxergava de modo algum dessa maneira, mas, pelo contrário, entendia a arte moderna como uma argamassa que unia diferentes pessoas interessadas em uma sociedade liberal antiautoritária.

5. Esta exposição deveria mostrar à Europa o quão avançada e moderna era a arte americana. Ao invés disso, devido a ataques da ala direita do Congresso e da imprensa, a exposição preparada pelo Departamento de Estado teve que ser repatriada para a Polônia, e os trabalhos, vendidos em leilão. Ver LITTLETON, Taylor D. \& SYKES, Maltby. Advancing American Art: Painting, Politics, and

Cultural Confrontation at Mid-Century. Tuscaloosa: The University of Alabama Press, 1989.

6. Em 1946, numa ofensiva totalmente moderna, o MoMA incentivou a ideia da educação artística ao criar em seu porão um Museu de Arte Moderna para crianças, onde os jovens visitantes podiam tocar em contravam no coração da arte moderna. É por esse motivo que a versão de modernismo proposta pelo MoMA foi exportada para o exterior com paixão, expandindo as suas operações para a América do Sul, bem como para muitos estabelecimentos franqueados onde a fúria anticomunista estava substituindo o antifascismo depois de 1946. Esse tipo de entusiasmo missionário não foi uma tarefa fácil e nem sempre teve sucesso, como atesta o fracasso da (não) famosa exposição "Advancing American Art" ${ }^{\text {, }}$ mas era, no entanto, considerado elemento essencial para a reconfiguração do mundo ocidental pós-guerra ${ }^{6}$.

Essa cruzada em prol da proteção e do desenvolvimento da arte moderna foi importante no final dos anos 1940 quando a arte moderna tornou-se não apenas um sinal da modernidade, progresso, liberdade e individualidade, mas também a imagem inversa do temido realismo social, da arte orientada à comunidade, da propaganda e da manipulação simbolizadas por dois regimes autoritários: a Alemanha nazista e a Rússia comunista. Essa é uma das razões pelas quais, desde o fim da guerra, Nelson Rockefeller encorajava o Brasil a se abrir aos valores modernos e a desenvolver uma democracia liberal; e, para tanto, ele estava preparado para ajudar ativamente aqueles que se lançassem em tal empreendimento.

Em novembro de 1946, Nelson estava ocupado preparando uma importante viagem ao Brasil para enaltecer os valores e a cultura do "American way of life". Dois dias antes de partir, como num pensamento tardio, ele teve uma ideia que teria importantes consequências. No fim de semana antes de sua partida, Rockefeller pediu a seu secretário e a Dorothy Miller, do MoMA para que fizessem uma série de compras em galerias modernas de Nova Iorque para chegar ao Brasil com as últimas produções modernas da capital americana. O plano era doar essa coleção de pinturas feitas por artistas jovens, ao redor de seus 30 anos (Alexander Calder era o mais velho, com 48), para o país como presentes, ou melhor, como uma forma de sedução, por meio deste exemplo, para colecionadores brasileiros seguirem e iniciarem um movimento de compra de arte moderna e contemporânea, enquanto estariam comprando, ao mesmo tempo, toda a ideologia do progresso, juventude e "liberdade". Dez quadros foram transportados de avião ao Brasil pelo próprio Rockefeller. Eles eram, como foi enfatizado, todos (incluindo aqueles feitos por europeus) feitos nos Estados Unidos, de modo a reforçar o poder criativo do solo americano: Jacob Lawrence, Alexander Calder, Byron Browne, Max Ernst, Robert Gwathmey, Morris Graves, George Grosz, Fernand Leger, Andre Masson, Arthur Osver, Everett Spruce, Yves Tanguy and Marc Chagall ${ }^{7}$.

Em uma carta de novembro de 1946, o Museu de Arte Moderna chegou a sugerir a Kneese de Mello que o MoMA previsse o emprésti- 
esculturas e apreciar pinturas modernas para que, por toda uma geração, crescessem com essa nova linguagem, sem medo e sem preconceitos. Esse foi um dos primeiros programas que tentou convencer (educar) crianças sobre a importância da educação da arte moderna. 0 fato de que a arte moderna era boa deveria ser aceito. Era como uma nova escola dominical, um tipo de catecismo modernista.

7. Tudo isso está respeitosamente registrado em uma carta de novembro de 1946, nos Arquivos da Fundação Rockefeller (III4L, Caixa 148). Museu de Arte Moderna para crianças, onde os jovens visitantes podiam tocar em esculturas e apreciar pinturas modernas para que, por toda uma geração, crescessem com essa nova linguagem, sem medo e sem preconceitos. Esse foi um dos primeiros programas que tentou convencer (educar) crianças sobre a importância da educação da arte moderna. 0 fato de que a arte moderna era boa deveria ser aceito. Era como uma nova escola dominical, um tipo de catecismo modernista.

8. BARR, Alfred. Introdução de What is Modern

Painting?, de 1943, revisado em 1945,1946 1949, 1952, 1956. Em português: BARR, Alfred. Introdução à Pintura Moderna. Tradução de João Azenha Jr. São

Paulo: Martins Fontes, 1988 (N.T.).

9. Carta de Nelson Rockefeller a Henri Luce, de 24 de março de 1949 mo de uma mostra pronta para exportação, preparada por Alfred Barr, intitulada "What is Modern Painting?", planejada para "divulgar" a arte moderna. Essa era, sem dúvida, uma referência ao livreto homônimo de Alfred Barr, publicado em 1943 e reimpresso pela terceira vez em 1946 (com 45.000 cópias vendidas até então). A natureza didática desse livro e o efeito esperado da mostra na disseminação de valores liberais não podem ser superestimados, como Barr promove em seu texto de forma claramente visível. O que a defesa da arte moderna - mesmo a mais radical - significou em termos globais foi, na mente de Rockefeller, a liberação do espírito progressista. Isso foi o que ele descreveu ao tentar convencer o inculto Henry Luce, da Life Magazine em 1949, a dar o seu apoio à arte moderna, já que esta representava verdadeiramente a assim chamada "Free enterprise painting" . Não se deve enfatizar demais esses sinais de esforço concentrado por parte do MoMA e de Nelson Rockefeller em dar suporte à arte moderna por correr-se o risco de dar a impressão de que havia uma conspiração no ar, mas não se pode ignorar o fato de que havia uma confluência de eventos que poderia explicar o aumento do interesse latino-americano pela arte moderna que se deu com uma leve ajuda de alguns amigos bem posicionados em Nova Iorque. Essa ajuda andava de mãos dadas com o desejo e a necessidade de Rockefeller de acabar com os sindicatos de esquerda e com os partidos comunistas em toda a América Latina. Peter Collier e David Horowitz, em seu livro The Rockefellers: An American Dynasty (1976), mencionam que em 1944 Serafino Romualdi, um amigo de Nelson, andava ocupado em criar sindicatos não comunistas na América Latina ${ }^{10}$. Não se deve esquecer que a forte manifestação do Partido Comunista nas eleições brasileiras de 1945, então com 180.000 membros (o maior partido comunista da América Latina da época) deu um banho de água fria nos escritórios do Departamento de Estado em Washington: "Dificilmente uma cidade (...) com mais de 1.000 habitantes não tem uma sede comunista exibindo abertamente a foice e o martelo (...) [e] ativamente engajada em tentar envenenar as mentes dos camponeses e trabalhadores principalmente contra os Estados Unidos e, em menor escala, contra o governo brasileiro" ${ }^{11}$, disse o Embaixador William Bentley do Rio de Janeiro em 1946. Também é interessante notar que, precisamente na hora em que a ideia de um Museu de Arte Moderna apoiado por Nelson Rockefeller é desenvolvida em São Paulo, grandes e violentas greves estavam perturbando a economia brasileira e poderiam encontrar $100 \%$ de adesão nas fábricas metalúrgicas e têxteis da mesma cidade. Sem dúvida, o conglomerado industrial de Matarazzo estava apreensivo e buscava diversas soluções. Entre 1947 e 1948, as coisas mudaram consideravelmente no Brasil quando o Partido 
(documentos de Alfred Barr dos Arquivos de Arte Americana, Washington D.C. Roll 2171).

10. Ver COLLIER, Peter \& HOROWITZ,David. The Rockefellers: An American Dynasty. Nova lorque: Holt Rinehart Winston, 1976, p. 263.

11. Documento secreto enviado pelo embaixador William D. Pawley do Rio de Janeiro a Washington D.C. no dia 16 de agosto de 1946, RG 59/832.00B/8-1646, citado por Leslie Bethell em Latin America Between The Second World War and The Cold War, 19441948, editado por Leslie Bethell e lan Roxborough (Cambridge: Cambridge University Press, 1992, p. 61).

12. AFL: Federação Americana do Trabalho e Congresso de Organizações Industriais, do inglês American Federation of Labor and Congress of Industrial Organizations (N.T.).

13. Carta de Lawrence H.Levy a Nelson Rockefeller, nos Arquivos da Fundação Rockefeller, Caixa 148, Pasta 1464.

14. BARR, Alfred. Op. cit., p. 05
Comunista Brasileiro, o PCB, foi finalmente considerado ilegal e todos os seus representantes eleitos barrados do poder em janeiro de 1948. A onda anticomunista rapidamente tomou conta de São Paulo e do Rio de Janeiro, onde as organizações sindicais comunistas eram tradicionalmente bastante fortes. Elas foram substituídas por uma Confederación Interamericana de Trabajadores, patrocinada pela $\mathrm{AFL}^{12}$, em oposição a uma confederação comunista (CTAL). Essa tática de organizar os sindicatos trabalhistas também estava ocorrendo na maior parte dos países europeus, particularmente na Itália e na França. Tudo isso para ressaltar o fato de que a ascensão da ideia de arte moderna, e particularmente da abstração contemporânea, ocorreu em larga escala e foi santificada principalmente por instituições privadas que coincidiam com a eliminação da oposição comunista anterior ao início da Guerra Fria.

Nesse perigoso campo minado política e economicamente, a arte moderna era convocada a desempenhar um papel crucial no esforço de prover um antídoto para o vírus comunista. A arte e cultura poderiam ser recrutadas para essa batalha crescente. No dia 26 de dezembro de 1946, por exemplo, em correspondência com Nelson Rockefeller, Lawrence Levy propôs uma solução interessante para o problema da agitação dos trabalhadores: ele recomendou a "exibição de filmes de entretenimento (16mm, emprestados pelo MoMA) aos trabalhadores, filmes que indiretamente [iriam] enfatizar o estilo de vida democrático, e assim combater o comunismo entre os trabalhadores, o que o Sr. Byington afirmava que [estava] em ascensão" ${ }^{13}$. Na medida em que a divulgação da arte moderna aumentava, o que estava sendo trazido à tona, após a fase de limpeza, era uma arte baseada no individualismo, no internacionalismo e no progressismo. Seja moderno e ousado, era a mensagem que Alfred Barr estava enviando ao público contemporâneo através de seu influente What is Modern Painting? De acordo com Barr, todos poderiam ser pioneiros, sem dúvida ou receio. Esses artistas, enquanto "antenas sensíveis da sociedade", estavam diretamente ligados aos assuntos contemporâneos cruciais: "Os artistas modernos se relacionam com os problemas cruciais de nossa civilização: a guerra, o estilo democrático e tirânico, os efeitos da industrialização, a exploração do pensamento subconsciente, a sobrevivência da religião, a liberdade e a repressão do indivíduo"14. O livreto estava obviamente atacando vários dos assuntos quentes da Guerra Fria com entusiasmo e devoção. O fato de que hoje o tom do panfleto se pareça com ladainhas missionárias mostra a urgência com que Barr e outros perceberam o âmago da arte moderna.

Mas a luta pelo reconhecimento da modernidade - dada a sua 
15. Ver a carta de Nelson

Rockefeller a Sérgio

Milliet publicada por Aracy Amaral (AMARAL, Aracy. A História de uma Coleção. In: Perfil de um Acervo: Museu de Arte Contemporânea da Universidade de São Paulo. São Paulo: Ed. Ex-Libris, 1988, p. 14].

16. Em sua apresentação sobre a correspondência entre o MoMA e os Museus Modernos brasileiros, Aracy Amaral mostra o quão politicamente importante foram essas tentativas. Em uma carta de Sprague Smith, do MoMA, para Sérgio Milliet, fala-se que a futura organização “é de importância suprema para o desenvolvimento cultural do hemisfério" (Idem, ibidem, p. 15). Sem dúvida, Rockefeller via 0 artista individual moderno como vital para os Estados Unidos e para o Brasil em sua batalha liberal contra o socialismo. importância ideológica - seria dura, já que estava ficando cada vez mais claro que o mundo pós-guerra dividia-se rapidamente em duas linhas antagônicas representadas por diferentes perspectivas culturais (Abstração versus Realismo). Vista de Nova Iorque, a cultura ocidental tinha dois caminhos a escolher: a arte moderna significando o impulso do indivíduo preparado para o combate em direção à liberdade em uma sociedade fluída e aberta e a arte realista representando modelos estéticos pré-determinados e as mensagens propagandísticas em apoio a uma sociedade monolítica e fechada. É claro que as coisas eram um pouco mais complicadas do que isso. De fato, a abstração geométrica havia oferecido no passado, assim como no presente, um futuro socialista específico do tipo que alguém como Rockefeller, por exemplo, não poderia ver nem compreender. Apenas o componente individualista da equação era percebido e divulgado. Havia ainda o medo de que o caminho para a aceitação de tal arte no Brasil fosse, de acordo com Nelson Rockefeller, tão árduo como havia sido e ainda era nos Estados Unidos. Mas Nelson estava pronto para apoiar essa importante inserção no Brasil ao apresentar parte de sua coleção para dois novos prósperos centros urbanos, São Paulo e Rio de Janeiro para, como escreveu a Sérgio Milliet, "acelerar um momento latente" 15 , um momento que estava sendo estimulado a toda velocidade através da doação daqueles trabalhos anteriormente mencionados, que foram colecionados em 1946 na esperança de que esses recém-construídos Museus Modernos fossem criados e organizados no estilo do bem-sucedido MoMA, em Nova Iorque ${ }^{16}$.

Foi durante esses diferentes tratos e declarações sobre arte moderna que Matarazzo viu a luz moderna e decidiu abrir um museu de arte moderna em São Paulo após muitas discussões com o casal de intelectuais e artistas Carlos e Moussia Pinto Alves, em clara oposição ao gosto de outro magnata, Assis Chateaubriand, que já tinha um Museu de Arte Moderna, mas de características muito mais tradicionais (com Degas, Cézanne etc.). A disputa centrava-se na construção de uma nova estética "moderna". Já no final de 1946, Rockefeller estava ciente do projeto audacioso de Matarazzo: o de investigar e encorajar. De acordo com Carleton Sprague Smith, "Chateaubriand não poderia ficar esperando na fila, de maneira que o museu na Diários Associados estava construindo um pot-pourri de vários estilos" ${ }^{17}$. Apesar desta íntima relação, Rockefeller ficou bastante surpreso quando soube da colaboração entre Matarazzo e Léon Degand, que culminou na abertura do Museu de Arte Moderna de São Paulo, em 1948. A súbita aparição de Degand em cena foi uma grande surpresa para a administração do MoMA, pois 
17. Carta de Carleton Sprague Smith para Nelson Rockefeller, de 1946, nos Arquivos da Fundação Rockefeller. No arquivo há um relatório (Caixa

148, Pasta 1464) que mostra a atenção dada ao potencial de criação

de museus modernos em São Paulo e no Rio de Janeiro. Depois de discussões por carta com Carlos Pinto Alves, Rino Levi (São Paulo), Manuel Bandeira, Anibal Machado, Plínio Rocha, Flavio Régis do Nascimento e Rubens Borba de Moraes

(Rio de Janeiro), fica claro que o MoMA estava tentando desviar o direcionamento dado pela "alta sociedade" para um museu que fosse mais orientado ao público: "parece que alguns 'granfinos' (Sr. Castro Maial têm tentado dar início ao Museu a partir de um princípio 'exclusivo', limitando os seus membros ao alto nível da sociedade".

Foram escritas cartas para o Sr. Moraes e para o Sr. Nascimento apontando a necessidade de uma "aproximacão" entre socialites. artistas e intelectuais e o público, para melhores resultados. A mesma situação do Rio de Janeiro ocorreu em São Paulo. as discussões sobre a criação do museu brasileiro supostamente sob a tutela do MoMA haviam se arrastado por muito tempo sem uma resolução específica. Matarazzo, na verdade, em uma carta para Nelson Rockefeller datada de 1947, a qual o MoMA parece ter se esquecido, mencionou o seu desejo de organizar uma mostra sobre a nova arte abstrata produzida em Nova Iorque, Londres e Paris.

De fato, a colaboração entre Matarazzo e Degand havia tornado obsoleta a intenção institucional do MoMA em estabelecer um museu de arte moderna no Brasil. Em fevereiro de 1948, René Drouin, o comerciante de arte francesa que estava em Nova Iorque preparando a exposição para São Paulo juntamente com Leo Castelli, tentou sem sucesso contatar e discutir o projeto com Nelson em um jantar festivo antes de sua partida para uma viagem de negócios. Drouin queria ainda convidar Alfred Barr para a abertura da mostra em São Paulo. Como a viagem era aparentemente muito cara (alguma incompreensível relação mesquinha entre Nelson e Barr), Barr ficou em Nova Iorque, mas concordou em emprestar três trabalhos abstratos para a mostra inaugural do museu (Malevich, Lissitsky e Loren MacIver). Toda essa intensa atividade forçou Dorothy Miller, no dia 23 de julho, a refrescar a memória da equipe do MoMA sobre a importância da exposição brasileira de 150 obras abstratas. No dia seguinte, D'Harnoncourt enviou um telegrama a Suzanne Cable, do MoMA, perguntando nervosamente: "O que está acontecendo?”. Ninguém no MoMA realmente sabia, mas foi rapidamente compreendido que a instituição havia sido ludibriada. Tanto assim que tiveram que recusar a oferta de Matarazzo de emprestar a exposição preparada por Léon Degand e René Drouin para o MoMA (carta de 15 de setembro de 1948). Era como se o MoMA de Nova Iorque, não mais capaz de influenciar o destino de um incipiente museu de arte no Brasil, decidisse cortar os laços.

\section{Construindo o sonho de Matarazzo a partir do mundo de Léon Degand}

Uma vez que decidiu se tornar um promotor da pintura moderna ao invés de um simples coletor de arte moderna tradicional, Matarazzo, de descendência napolitana, contatou outro amigo napolitano-brasileiro, Aldo Magnelli, meio-irmão de um pintor abstrato em Paris, Alberto Magnelli, que estava profundamente envolvido na defesa da tradição da Abstração Geométrica na capital francesa. A abstração, logo após a Liberação, teve certa circulação em Paris, já que muitos artistas estavam buscando uma nova forma 
moderna, distante do temido e retrógrado realismo. A abstração, em círculos progressistas, era construída como humanista, universal, pura e prospectiva em sua modernidade. A última produção era apresentada a cada ano em um salão popular chamado "Salon des Réalités Nouvelles", que mostrava um amplo panorama de obras abstratas internacionais, nas quais tendências contraditórias geralmente conviviam sem grandes problemas. As pinturas geométricas utópicas dialogavam com o expressionismo pessimista. Curiosamente, a produção abstrata foi um assunto bastante corrente e também universal naquele momento.

Quando Matarazzo chegou a Paris em 1947 à procura de pinturas para o seu novo museu, Magnelli naturalmente o apresentou ao seu grande amigo Léon Degand, o crítico de arte nascido na Bélgica e defensor da abstração geométrica que estava ainda trabalhando para o jornal comunista Les Lettres Françaises. Ambos imediatamente perceberam que precisavam um do outro. Degand buscava uma alternativa para a sua carreira jornalística, colocada em constante perigo em função de seu aguçado interesse pela abstração, um tipo de arte cada vez mais considerada pelo Partido Comunista como um plano para destruir a moral da classe trabalhadora. Matarazzo, por sua vez, precisava de um especialista para lhe ajudar a adquirir a arte mais avançada do momento e mostrar ao Brasil que ele e o país estavam se movendo rapidamente em direção à modernidade, a uma sociedade urbana sofisticada que merecia a atenção das nações industrializadas em meio ao processo de reorganização do mundo ocidental. A arte moderna, em sua fase mais avançada, firmou-se como um poderoso símbolo do progresso pós-guerra. Não apenas isso, mas a escolha da arte, um tipo de obra geométrico-abstrata ultramoderna com sua construção universal, era um sinal de que a arte socialmente orientada produzida por artistas realistas como o famoso brasileiro Candido Portinari estava ultrapassada e relegada a um tempo que rapidamente se distanciava dos interesses locais. A arte abstrata, em sua forma pura, tornou-se um símbolo de criatividade individual, de uma entidade única moderna e distinta, livre das preocupações diárias, a expressão de um mundo moderno, urbano e racional. Esse era de fato o discurso empregado por Degand no catálogo produzido para a abertura do museu em São Paulo. Degand repetidamente dizia o mesmo que defendia na Europa desde o final da guerra: que a arte abstrata era o produto visível de uma tendência tradicional na arte modernista rumo à autonomia em relação a um mundo exterior. A abstração, ele dizia, era a criação ao invés da representação, um espaço livre onde a criatividade individual e a experimentação poderiam se expressar em total independência. 
18. Ver LÉVY STRAUSS, Claude. Tristes Trópicos. Tradução de Wilson Martins. São Paulo: Anhembi, 1957, p. 97
Esse tipo de imagem parecia se encaixar muito bem no novo desenvolvimento que se testemunhava no Brasil. De fato, o país estava colocando em prática, depois de uma breve avalanche de democratização após 1945, um governo rigidamente controlado, administrado por uma economia livre. Assim como Matarazzo estava deslumbrado com a nova linguagem abstrata que a arte moderna proporcionava, também Degand estava extasiado com o ímpeto urbano brasileiro em direção à modernidade. Eles pareciam estar programados para se encontrar, embora Degand nunca tenha entendido as complicadas implicações simbólicas, políticas e ambientais que estavam ligadas à modernidade brasileira. Ele nunca compreendeu totalmente que a implantação de um museu moderno em São Paulo viria a reforçar uma cultura litorânea colonizada e tradicional que desde a chegada dos portugueses estava voltada para o comércio e para as relações com a Europa. As forças responsáveis por marginalizar o interior, aparentemente aproximando o Brasil de uma classe executiva internacional arrogante e voltada para o exterior, geravam ressentimento. Enquanto diretor de uma importante nova instituição, Degand caiu na armadilha desse discurso sobre espaço colonizado e espaço colonizador, sobre velhos e agressivos debates nos quais a sua voz europeia - apesar de sua crença no contrário (para ele a alta arte era Civilização) não poderia deixar de alimentar suspeitas e ressentimentos. $\mathrm{O}$ projeto iluminista por trás da criação e do apoio à arte abstrata moderna estava, em muitos sentidos, reativando um mecanismo de dominação onde a liberdade de um se tornaria a norma autoritária de outro.

Degand estava muito impressionado com a notável vitalidade de São Paulo, que também havia tão profundamente impressionado Claude Levi-Strauss em Tristes Trópicos: "Em 1935 os paulistas se gabavam do ritmo de construção em sua cidade; a média de uma casa por hora. Tratava-se, então, de palacetes; asseguraram-me que o ritmo continua o mesmo, mas para os grandes edifícios. A cidade desenvolve-se com tal rapidez que é impossível encontrar-lhe um mapa: cada semana exigiria uma nova edição"18.

Esse desejo de se tornar supermoderno a todo custo era uma doce música para os ouvidos de Degand, que havia lutado contra um público ignorante em Paris. Ele pensava que a virgindade cultural que tinha percebido em São Paulo era a sua chance. Degand poderia finalmente trabalhar em um laboratório de modernidade sem o impedimento do academicismo e conservadorismo que eram o fardo de países mais antigos como a França. Essa era a sua chance de tornar mentira uma cruel e famosa piada do continente americano, repetida por Lévi-Strauss em Tristes Trópicos, que dizia que a América era o único lugar no mundo que passou da barbárie à decadência sem ter sido civilizada no entremeio. 
Degand estava determinado a mostrar aos céticos o que ele poderia fazer no novo solo virgem e fértil: ele enxertaria uma ideia mal compreendida pela Europa nesse novo mundo e a veria florescer. Esse poderia ser um movimento realmente libertário, distante das areias movediças da vida intelectual conservadora da França. De fato, Degand estava envolvido em uma luta importante, mas também deprimente. Ele estava confrontando uma ofensiva comunista antiabstracionista e o desenvolvimento a passos largos da arte social realista. Esse assunto se tornou central para Degand enquanto negociava com Matarazzo, já que estava a ponto de ser substituído na Les Lettres Françaises por outro crítico de arte mais interessado na linha realista: Georges Pillemment. Essa era uma mudança de estratégia realmente importante para o Partido Comunista que, com a ajuda de Moscou, decidiu apoiar exclusivamente o Realismo Socialista e atacar insistentemente a abstração e a conspiração da burguesia decadente designada a enfraquecer a consciência da classe trabalhadora. $\mathrm{O}$ fato de que o salão abstrato chamado "Salon des Réalités Nouvelles" tenha sido amplamente constituído por artistas abstratos americanos era uma desculpa a mais para a campanha feroz do partido comunista. Uma vez desempregado, o frustrado Degand não parou, pois apesar de seus incansáveis esforços, ele foi incapaz de promover a sua Abstração Geométrica "universal" no mundo da arte parisiense, já que estava confrontado com o poder da renovada Escola de Paris. Renomados críticos e historiadores da arte como Bernard Dorival, Pierre Francastel, Jean Cassou e Gaston Dhiel enfatizaram a qualidade e o humanismo da Escola de Paris, rejeitando a abstração total. Até mesmo no Primeiro Congresso de Críticos de Arte Internacional, do qual Degand participou algumas semanas antes de vir para o Brasil, ele teve que ouvir diversos discursos de exaltação à grandeza da cultura parisiense, embora fossem discursos estruturados para obter consensos. A arte - especialmente aquela produzida em Paris - era, ou deveria ser, naturalmente antinacionalista, internacional e até mesmo, na mente de Jean Cassou, universal. Jean Cassou, que havia sido recém-escolhido diretor do então reaberto Museu de Arte Moderna de Paris, declarou confiantemente a uma plateia de críticos de arte que "a arte é uma linguagem universal e que a arte francesa, desde o século XIX, tem sido universal. Ela representa uma aventura espiritual maravilhosa que precisa da participação de todos os países. A arte francesa sempre foi a encarnação do humanismo e possui um poder de atração e expansão”. Essa era a tradicional pauta parisiense de defesa às vésperas da Guerra Fria. Entretanto, o belga Léon Degand, bem como o crítico italiano Guido Ludovico Luzzatto, haviam apresentado no encontro algumas sérias restrições sobre essa visão. Na verdade, Luzzatto confrontou o "colonia- 
lismo cultural de Paris" durante uma sessão presidida pelo próprio Jean Cassou. Luzzatto abruptamente declarou que toda a conversa sobre universalismo era muito interessante, mas que "deve-se observar que esse Congresso se coloca inteiramente ao lado do internacionalismo porque a avaliação crítica que domina aqui é a avaliação crítica de Paris”. Jean Cassou se sentiu obrigado a lembrar que Paris não confundia universalismo e imperialismo, já que era uma capital aberta a todas as culturas estrangeiras. Obviamente, para Cassou, a aura de Paris era tamanha que o fato de que algo válido ou interessante pudesse ser produzido em outros lugares era impensável. Ele afirmou à sua plateia que Paris era o centro mais importante e criativo, e que era também benevolente neste sentido. Se estou me alongando em relatar sobre tal Congresso é porque quero enfatizar as frustrações que motivaram Degand a buscar em outros lugares a implementação de seu programa neomodernista, uma visão que o separaria das receitas erradas reproduzidas pela Escola de Paris, promovidas por Cassou e pelo establishment francês, bem como pela retórica comunista.

Desde 1946, uma série de livros escritos por Bernard Dorival e Pierre Francastel definia as qualidades específicas da pintura parisiense. Elas eram o oposto de como a arte alemã deveria ser: expressionista. A arte francesa era um tanto cartesiana, com gosto, delicadeza e razoável beleza, reconstruções profundamente enraizadas em convicções nacionalistas. Essa ideologia via o homem como parte da natureza, mas sem desestabilizar o efeito dos instintos: no homem, a natureza se confunde com a razão, pois a natureza do homem não é nada mais do que o instinto controlado pela razão. Assim, Dorival rejeitou Mondrian e Kandinsky, preferindo a reserva elegante de Leger e Modigliani. Era disso, em grande medida, que León Degand estava tentando escapar, era essa a razão pela qual ele pensava que as obras de Mondrian e Kandinsky eram cruciais para a sua mostra e o porquê dele particularmente gostar da obra de Magnelli, uma obra que, ao introduzir fantasia e elementos formais emocionais, negligenciava consideravelmente os parâmetros ortogonais geométricos puros. Sendo assim, por outro lado, Degand desprezou a linha realista simplória - ele até mesmo escreveu contra a mostra de Portinari em Paris, para a ira de André Fougeron, pintor social realista do Partido Comunista - e defendeu o abstracionismo total, que concebia como a produção cultural mais avançada de seus dias. No entanto, é importante lembrar que essa era uma abstração não totalmente dependente da definição do "Cercle et Carré", mas uma abstração aberta ao sentimento, à intuição, à pintura/ pintura mais próxima da música. $\mathrm{Na}$ definição de Degand, era necessário ter simplicidade de pensamento e também de coração para entender a pintura abstrata, para poder aces- 
19. Léon Degand para Paul Eluard em carta datada de fevereiro de 1947, nos Arquivos do Centre Pompidou,

Paris. sar a nova linguagem sem preconceitos, sem tentar nela ler a natureza a todo custo. Em outras palavras, a pintura abstrata era um retorno a algum tipo de origem revigorada. Para ele, o Brasil poderia oferecer esse recomeço. Em sua busca pelo desenvolvimento de uma nova linguagem que representasse a nova era moderna, Degand sentiu que o trabalho de seu amigo Alberto Magnelli era uma epítome da pintura moderna. Magnelli costumava a dizer "Nós precisamos de uma forma clássica como a pintura abstrata", uma forma clássica clara, distanciada das "manchas" sujas que estavam na moda. Magnelli usava formas claras, sem exuberância, mas com humor, com óleo mas sem o temido aspecto escorrido. "Magnelli", disse Degand, "fala por si mesmo, longe de qualquer tipo de propaganda visual”. Esse tipo de abstração, clássica mas ainda intuitiva sem ser selvagem, era a arte do "presente" porque ela gerava otimismo sem ser escravizada pela geometria pura. "Na abstração", continuou Degand, "utiliza-se a inutilidade, o supérfluo, como os cigarros, o sono e o amor". Ainda assim, a arte abstrata não é irracional, argumentava Degand, em 1947, com seu amigo marxista, o poeta Paul Eluard - que, apesar de uma dose de confusão, estava seguindo a linha estrita do Partido Comunista. Para o comunista Eluard, a música, assim como a arte abstrata, muitas vezes levava as pessoas à beira do total encantamento, de serem manipuladas sem qualquer contato com aquilo que era essencial para um comunista: a realidade. Em defesa do abstracionismo, Degand imediatamente respondeu ao questionar Eluard, o poeta do amor: "Mas temos necessariamente que condenar aquilo que nos fascina? E na verdade, temos que rejeitar o amor, juntamente com a música e a pintura abstrata?" ${ }^{19}$. Ele finalmente enfatizou o ponto em que, ao contrário do que o partido pensava, a abstração não era intrinsecamente mística, mas poderia ser, é claro, imposta ao espectador. Isso era incontrolável.

Mas o prego no caixão geométrico de Degand foi cravado quando o "Prix de la critique 1948" foi dado a dois pintores que ele achava abomináveis: Bernard Lorjou e Bernard Buffet. Ainda que os pintores tenham sido escolhidos como forma de contestar o sucesso controverso do pintor realista socialista André Fougeron no "Salon d'Automne", este prêmio finalmente convenceu Degand do abismo no qual a pintura francesa moderna havia sucumbido. Em 1947, parecia que toda a vitalidade que a libertação prometera estava estagnada em um já conhecido lamaçal francês, enquanto os sonhos de rápida modernização do país se esvaíam. E, para acrescentar a essa decrepitude, como um sinal, por assim dizer, Jean Cassou abriu o Museu de Arte Moderna em 1947 sem apresentar o Surrealismo, o Abstracionismo nem qualquer tipo de Expressionismo $^{20}$. Degand compreendeu sua difícil situação como o resultado das instituições administradas pelo governo, incapazes de mudar, 
20. Ver a exposição de arte moderna francesa enviada ao Museu Whitney, em Nova lorque, na primavera de 1947, quando toda a nova geração de jovens artistas parisienses foi apresentada com um resultado alarmante.

Clement Greenberg escreveu sobre a mediocridade da mostra e fez várias críticas à arte na França. Essa demonstração, juntamente com a frustração da mostra

Surrealista que ocorreu no mesmo ano, ajudaram os críticos a levantar uma série de questões sobre a sobrevivência de Paris enquanto centro hegemônico.

21. Carta de Degand a Matarazzo, Paris, 9 de julho de 1947, nos Arquivos da Fundação Bienal de São Paulo (publicada por Aracy Amaral, p. 18). de evoluir com o tempo, em outras palavras, incapazes de serem modernas, de seguir o fluxo, estruturalmente impossibilitadas de crescer outra vez como a história passada havia dolorosamente mostrado. Neste sentido, Degand estava no mesmo caminho de Nelson Rockefeller. Numa carta enviada a Matarazzo em que o encorajava a seguir seu sonho de criar um museu moderno, Degand explicou a importância da atividade privada no setor das artes. Ele demonstrou que todas as instituições na França se achavam incapazes de juntar as produções mais vigorosas em suas coleções: "Se existe alguma pintura de excelência, isso certamente não se deve à escolha dos curadores de museus, mas às doações privadas, como a de Camondo, que deixou sua refinada coleção como legado para o Estado. O Museu de Arte Moderna em Nova Iorque, um dos mais bonitos deste tipo no mundo todo, também é privado, não é uma empresa pública. Portanto, está nas mãos de indivíduos privados - já que o poder público demonstrou sua incapacidade - juntar as suas próprias coleções de arte e exibi-las nos museus”. Para Degand, o importante era ser moderno a todo custo, ser capaz de começar do rabisco e ousar, e ao mesmo tempo ser hábil para ensinar a um público ignorante sobre a beleza da liberdade e da individualidade modernas. O papel do indivíduo rico e iluminado era o de guiar um público desorientado em direção a um conhecimento moderno: "O público não entende nada de arte moderna. Ele deve ser educado mesmo sem ter essa intenção. No presente estado de coisas, são os disparadores, ou seja, indivíduos privados audaciosos, que devem educá-los. Sendo assim, seu papel está bem definido" ${ }^{21}$.

Sozinho com seu amigo Magnelli, que por sua vez estava cercado de inimigos, não foi uma surpresa o fato de que Degand abraçou a maravilhosa ocasião oferecida por Matarazzo. Para Degand, Paris estava obviamente muito fechada em seu passado, arrogantemente mas também desesperadamente transformando a si mesma em um velho e tradicional país provinciano. Degand acreditava que todo o espaço cultural e artístico da capital francesa era controlado e imobilizado pela política. $\mathrm{O}$ novo mundo pós-guerra precisava de mais imagens, mais espaços, de uma nova arte baseada na intuição e na invenção, e não em cópias de um mundo já falido. Ele ainda se sentia jovem, ele rumou para o oeste!

León Degand viu na proposta de Matarazzo de trazer obras de arte modernas para o Brasil não apenas um novo trabalho, mas também a possibilidade de zombar e talvez até de ofuscar Paris, aquela Paris velha e incapaz de abrir o seu Museu de Arte Moderna para a nova era. Conforme Matarazzo, Degand estaria apto a abrir um novo espaço onde a história da abstração, em toda a sua glória e otimismo, poderia ser ex- 
22. Ver o seu "Une critique d'art en Amérique du Sud", texto manuscrito encontrado nos arquivos do Centre Pompidou, Paris, p.4. posta, enfatizando a deslumbrante liberdade da criatividade que a arte moderna trazia. E onde mais se poderia conceber isso além de São Paulo, um lugar cheio de nova vitalidade selvagem, em um novo continente onde o peso da tradição e do preconceito, Degand estava certo, estava ausente. Ele via a si mesmo como um novo missionário, provendo o novo mundo com as ferramentas estéticas capazes de ajudá-lo, não apenas a despertar os charmes do modernismo, mas também a despertar linguagem de uma modernidade cotidiana. Esse não era o momento de recriar o passado. Aqui havia uma verdadeira chance de começar de novo, de literalmente inventar um novo mundo, de trazer, de uma só vez, a sinfonia da abstração à vida: uma linguagem para o novo mundo.

Pelo menos esse era o pensamento e o sonho. Esse foi um sonho, apesar da imaginação dos europeus a respeito da América do Sul. Durante muito tempo os europeus haviam fantasiado acerca de uma espécie de mundo exuberante, tropical, livre, não domesticado um pouco selvagem mas ousado e criativo que caracterizava a América Latina. Foi com essa perspectiva que Degand chegou a São Paulo, pronto para criar livremente, agora que, ao contrário de Paris, o Partido Comunista, como ele rapidamente se deu conta, não poderia interferir em seu projeto, já que ele havia sido recém-banido pelo governo brasileiro enquanto o Plano Marshall era posto em prática na Europa. Degand chegou, na verdade, em um momento crucial da relação entre os Estados Unidos e a América do Sul. De fato, um novo arranjo estava se formando devido ao comprometimento financeiro dos Estados Unidos com a Europa através do Plano Marshall. Isso foi aquilo que o General Marshall explicou na Conferência Interamericana no Rio de janeiro, em 1947: a América do Sul deveria confiar na iniciativa privada para o seu desenvolvimento ao invés de confiar na ajuda do governo dos Estados Unidos, como ocorria antes. De um modo geral, o projeto privado de Matarazzo de criar um Museu de Arte Moderna em um importante centro industrial era bastante oportuno e exemplar. A arte abstrata sinalizava a passagem para a modernidade de um país simbolicamente liderado por um empreendedor em um caminho livre do comunismo.

Vamos voltar a 1947, quando Degand encontra Francisco Matarazzo Sobrinho, a quem gostava de chamar, sem desdém, de "um tipo de reizinho da lata”22. Desde o início, o projeto de Matarazzo consistia, após uma exposição acompanhada por uma série de palestras explanatórias, em abrir o Museu de Arte de São Paulo. Foi por esse motivo que ele viajou para a Itália em 1947 e comprou diversas pinturas modernas italianas de qualidade tal que Degand rapidamente as avaliou como desprezíveis e sem valor. Afinal, porque ir à Itália atrás de arte moderna se Paris tinha o melhor em casa: o 
23. A lista exibida em São Paulo é impressionante e diversificada: de Paris vieram Arp, Atlan, Bazaine, Dewasne, Deyrolle, Domela, Flexor, Freundlich, Gonzales, Hartung, Herbin, Hosiasson, Idoux, Lapicque, Leger, Le Moal, Magnelli, Manessier, Miro, Nouveau, Piaubert, Picabia, Poliakoff, Prassinos, Raymond, Reth, Schneider, Servranckx, Singier, Soulages, Van Velde Geer and Bram, Vasarely, villon. pintor italiano abstrato, e amigo de Degand, Alberto Magnelli.

Magnelli, Degand e o comerciante nova-iorquino Karl Nierendorf (especialista em arte abstrata) reuniram-se para elaborar um plano de ação e uma lista de artistas capazes de apresentar ao público brasileiro uma exposição que mostrasse a importância, a história, a qualidade e a diversidade da abstração. Esse era o plano base para a construção de um museu ideal de arte abstrata que fosse invejável para Nova Iorque e Paris. Em dezembro de 1947, Degand, Magnelli e Cícero Dias, um artista moderno brasileiro que vivia em Paris, encontraram-se novamente para finalizar a escolha. As complicações começaram desde o início, já que Nierendorf morreu repentinamente em Nova Iorque enquanto negociava com mercadores de arte e críticos sobre o projeto brasileiro. Degand encarregou-se totalmente da primeira exposição, bem como da edição de dois livros que apresentavam, através de textos de seu amigo crítico de arte Charles Estienne, uma pesquisa de todas as diferentes tendências na abstração desde a sua criação. O plano de exposição continha uma seção histórica, mostrando reproduções de trabalhos que indicavam o desenvolvimento do conceito de abstração desde Cézanne, uma seção que apresentava os mestres da abstração Mondrian, Kandinsky, Klee, Magnelli e, finalmente, duas seções que introduziam os jovens pintores abstratos da Escola de Paris e os jovens pintores abstratos de Nova Iorque ${ }^{23}$.

Sidney Janis e Marcel Duchamp, depois de encontrar-se com o francês comerciante de arte René Drouin, formaram o comitê de seleção por Nova Iorque. Drouin recebeu cinco mil dólares de Matarazzo para organizar toda a mostra. O envolvimento de Nova Iorque, através da insistência do comerciante de arte germano-estadunidense Nierendorf, bem como de Luis Carré, torna-se bastante interessante quando se sabe que o que estava particularmente em jogo naquele momento era a cultura hegemônica ocidental do pós-guerra. A lista enviada por Nova Iorque através de Leo Castelli, já ativamente envolvido no meio, continha todos os nomes dos futuros Expressionistas Abstratos. Em 1947 e 1948 eles já estavam prontos para exportação. A lista citava trinta e duas obras que incluía Willem De Kooning, Joseph Albers, Arshile Gorky, Adolph Gottlieb, Robert Motherwell, Jackson Pollock, Mark Rothko, Kay Sage etc., mais uma lista de pioneiros abstratos da coleção do Museu de Arte Moderna: El Lissitzky, Kazimir Malevich - um reagrupamento extraordinário de artistas modernos de importância específica quando se sabe que tanto em Paris como em Nova Iorque este estilo ainda não era reconhecido e era, muitas vezes, ridicularizado. 


\section{Cruzando o oceano}

24.A lista é muito longa para ser citada na íntegra, mas é interessante notar que Degand conseguiu juntar um grupo extraordinário de artistas diversificados - entre as maiores figuras estavam Kandinsky e Leger, juntamente com Kupka, Lapicque e Soulages.

25. Textos de Degand no Centre Pompidou, em Paris.
Durante o mês de abril de 1948, enquanto Paris estava em meio a uma greve geral induzida pelo Partido Comunista, Degand conseguiu, com grande dificuldade, juntar as pinturas de seus amigos artistas, encaixotá-las e embarcá-las rumo ao Brasil ${ }^{24}$.

Vamos fazer uma pausa momentânea e apreciar a imagem de uma carga repleta de pinturas abstratas que deixava um país atacado pela propaganda comunista e por greves de trabalhadores. O que pode ser visto nesse exercício é uma metáfora complexa e mista. Parece que essa viagem representa uma reencenação da descoberta do continente pela Europa. Degand traz para o litoral do Novo Mundo uma estética língua franca. Cheio de entusiasmo e zelo missionário, Degand, carregando em seus contêineres os produtos de uma nova linguagem simbólica que poderia representar, em seu radicalismo, a essência do mundo moderno, sonhava em estabelecer um poderoso império abstrato que estaria pronto, se fosse necessário, para revidar o velho continente. Degand e a arte ocidental estavam alcançando aquelas margens para dar forma e linguagem ao Novo Mundo, como os primeiros conquistadores fizeram na América, como se o território ainda fosse virgem, livre de tradições culturais (modernas ou outras). A invasão da arte europeia moderna no espaço sul-americano não era totalmente compreendida por Degand, que acreditava na semelhança entre o "frescor" desse continente e a vitalidade da abstração, sem entender que na verdade Matarazzo, em sua busca pelo poder, talvez inconscientemente tenha desempenhado o papel de um tipo de Malincha de calças (a amante nativa de Herman Cortez), importando elementos culturais estrangeiros, mas nem sempre se adequando ao ambiente. Léon Degand voou para o Brasil no dia 12 de julho de 1948 e encontrou o pintor Cícero Dias, que estava de férias em Recife. Lá, durante alguns dias, Degand teve tempo de experimentar certos estereótipos europeus sobre o Brasil ("cases de travailleurs négres dans les plantations de cannes á sucre") e admirou os afrescos ingênuos violentamente pintados nas paredes da pequena cidade de Cabo, antes de chegar a São Paulo, no dia 15 de julho. Durante esses oito dias, Matarazzo pediu a Degand para que ele se tornasse o diretor desse novo projeto de Museu de Arte Moderna, e Degand aceitou. Seus planos eram objetivos e incluíam uma longa mostra histórica de abstração precedida por uma série de conferências introdutórias por Degand sobre arte moderna: "Arte e público", "Picasso sem Literatura", "O que é a Pintura Figurativa?" e "O que é a Pintura Abstrata?"25 para preparar o terreno para uma abertura oficial que, no entanto, tardava a acontecer devido a 
problemas burocráticos. $\mathrm{O}$ museu, como foi mencionado anteriormente, refletia em muitos aspectos a organização do MoMA em Nova Iorque, apesar de algum receio de Degand. Ele estava particularmente atento à insistência em se ter comissões e departamentos artísticos para lidar com arquitetura, cinema, folclore, fotografia, artes gráficas e música juntamente com o departamento de pintura e escultura.

Logo em seguida, assim que os planos para o museu e para a primeira mostra foram esboçados, Degand começou a compreender que a sua posição era instável, já que ele progressivamente foi se dando conta de que o projeto era difícil de negociar devido às diferentes compreensões sobre o papel do museu entre todas as partes envolvidas (Matarazzo, funcionários, comerciantes de arte, imprensa). Enquanto o atarefado Matarazzo trabalhava em outros dos seus diversos negócios, Degand teve que enfrentar muitos problemas burocráticos acerca da conclusão do projeto (problemas com os administradores, dificuldades financeiras, com os arquitetos etc.). Ele via nisso tudo apenas uma série de ações burocráticas estúpidas ou simplesmente uma falta de "bom gosto" quando, na verdade, era uma técnica de atraso interessante para muitos partidos de São Paulo que resistiam à renovada imposição europeia. Desde o início, Degand se surpreendeu com a localização do museu, situado no piso remodelado de um edifício alto do centro de São Paulo. O museu estava localizado, como qualquer escritório corporativo, em um alto edifício envidraçado. Mas isso não condizia em nada com o que ele imaginava, já que ele havia vislumbrado um espaço de exposição bem específico e modernista. Este deveria consistir em um cubo branco com paredes brancas imaculadas que poderiam isolar o trabalho visualmente e focar o olhar em um único objeto/ pintura para a sua contemplação. Depois de algumas discussões dolorosas, o arquiteto concordou em seguir o conselho de Degand e bloqueou todas as janelas do segundo andar da exposição. Ele concordou com o pedido de Degand de adquirir cadeiras e poltronas para que os cansados e contemplativos corpos descansassem das caminhadas pelo museu. É claro que elas deveriam se adequar à seriedade do empreendimento: algumas foram cobertas de preto, outras de branco para realçar a frieza do esforço intelectual lá produzido. Depois de todo o empenho dedicado durante esses dias de organização, Degand, o mestre da cerimônia intelectual, resolveu passar alguns dias na praia onde ele pode ver e apreciar o frescor "popular", tão ingênuo e tão especificamente à vontade em uma vila, que ajudava a reforçar a forte distinção entre o interior e a cidade: frescores ingênuos para as pessoas do interior e arte abstrata para a nova sociedade industrial urbana. Tudo parecia estar claro e seguir a "ordem 
26. Manuscrito de Léon Degand intitulado "Une critique d'art en Amérique du Sud", encontrado nos Arquivos do Centre Pompidou, Biblioteca Kandinsky. das coisas". Mas depois de sua volta, a compreensão que tinha acerca dessa dualidade foi seriamente questionada quando foi confrontado com uma completa rebelião, uma revanche do clichê, por assim dizer. A natureza luxuriante e sensual brasileira parecia ter se virado contra o frio mecanismo de poder belga. Enquanto esteve de férias, os funcionários e o arquiteto decidiram transformar drasticamente o branco espaço moderno que estava disponível pintando as paredes com diferentes cores. Algumas, como Degand descreveu em seu relato escrito, "eram de cor azul prussiano, algumas vermelho-sangue, chocando-se violentamente com amarelos estridentes e beges banais e sem graça, sem mencionar o vermelho intenso do chão de madeira”. Em um acesso de raiva, Degand descreveu o local para um decepcionado Matarazzo como uma "arara multicolorida"26. Para aumentar o insulto, alguém havia colocado capas de flores coloridas nas cadeiras e poltronas, anteriormente feitas de couro preto e branco, transformando o ambiente branco imaculado em uma selva de sentidos, colocando à beira da catástrofe todos os preceitos abstratos que haviam sido cuidadosamente alinhados nas paredes. A batalha continuava e Degand, o velho sagaz opositor dos artistas do Partido Comunista e de seus críticos, viu-se sem palavras frente a essa inundação de cores e flores sensuais. Degand era o primeiro alvo, mas Matarazzo e sua aparente subserviente relação com a Europa também o foi. Para Matarazzo, qualquer avanço industrial deveria ser assinalado pela imagem de uma modernidade (europeia), não importando o custo simbólico que isso acarretasse para o local. Essa modernidade era o sinal de uma aliança de países modernos contra velhas atitudes ou pensamentos reacionários ou ainda, na melhor das hipóteses, contra um posicionamento conservador. Para Matarazzo, era importante diferenciar a si mesmo dos velhos e tradicionais apoiadores da arte clássica moderna, como a arte que havia sido recentemente defendida pelo magnata das comunicações Assis Chateaubriand, em um museu de São Paulo orientado para o Modernismo histórico. Ao lidar com o mais avançado experimentalismo da cultura contemporânea, o novo museu de Matarazzo era mais ousado e pioneiro em seu estilo verdadeiramente aventureiro e empreendedor. É por isso que Degand, sob diversos aspectos, era a peça chave de todo o mecanismo, sem que na verdade compreendesse isso. Para ele, a defesa de um tipo de arte que incorporava a liberdade do indivíduo e o desenvolvimento contínuo da história da arte moderna era a continuação, através de Mondrian e Magnelli, da linha estabelecida por Cézanne. Era o internacionalismo moderno o que também movia Matarazzo. Otimismo e fé no futuro foram fatores importantes nessa perigosa conjuntura. É por isso que a aliança e a representação da cultura moderna dos Estados Unidos e da Europa 
27. Ver o importante trabalho de Mona Huerta, La mise en place du dispositif français d'information scientifique et technique sur l'Amérique Latine. Cahier des Amériques Latines, n. 20, p.133-188, 1995. tinha tanta importância, enquanto tantas forças eram relutantes em olhar para frente sob a ameaça de uma nova guerra leste/ oeste e enquanto o nacionalismo ainda era um componente forte na política brasileira. A arte moderna, pelo menos para uma parte da intelectualidade internacional, estava atuando como salvadora não apenas da alma, mas também de uma noção de sociedade liberal internacional por si mesma.

O fracasso de Degand, então, parece ser o resultado de uma série de circunstâncias infelizes que tinham a ver com a falta de controle de Matarazzo sobre a situação e também com o entusiasmo cego do próprio Degand, ao invés da rejeição da abstração em si pelo público e pela intelectualidade brasileira. De fato, o museu finalmente veio a se tornar realidade mais tarde, particularmente depois da organização da primeira Bienal de São Paulo em 1959. Depois de muitas transformações e cortes, a mostra foi finalmente exibida, só que em uma escala muito menor, já que os trabalhos de Nova Iorque nunca foram enviados devido à falta de fundos e a incompreensões administrativas. Além disso, por razões semelhantes, as desejadas esculturas abstratas também ficaram nas docas de Le Havre, na França.

A nova aventura da arte moderna na América do Sul foi, na verdade, uma aventura triste, nada além de um espalhafato de fogos de artifício. Depois de encerrada a primeira exposição e de mais problemas burocráticos, Degand decidiu voltar à Paris. Em seu trajeto de volta, no entanto, ele tratou de promover uma nova exposição com a coleção em Buenos Aires, em julho de 1949, com 82 peças em lugar de 95, demonstrando, sem saber, que o seu fracasso era na verdade mais interessante e mais produtivo do que o esforço propagandístico feito pelo governo francês durante os importantes anos de reconstrução nacional. É verdade que o governo francês também estava tentando renovar a sua imagem cultural através de um programa de exposições muito medíocre apresentado ao redor do mundo (em particular a desagradável exposição no Museu Whitney em 1946, em Nova Iorque). Essa iniciativa francesa era generalizada, mas mais especificamente orientada para a América Latina em resposta à percepção de que os Estados Unidos estariam agora se tornando hegemônicos em uma região geográfica que a França havia tradicionalmente dominado desde a virada do século. A França reconhecia que a hegemonia cultural, na educação, literatura, arte, cinema etc. era também a chave para abrir mercados comerciais e, portanto, tinha de ser protegida ${ }^{27}$. A recepção da exposição privada de arte abstrata de Degand foi um caso característico quando se percebe o importante impacto popular e a influência que tal mostra teve no contexto argentino. A França era exageradamente aclamada como fonte de progresso cultural internacional, capaz de mostrar o caminho do futuro 
28. Cf. Ver y Estimar.

Cuadernos de Critica artistica, n. 11-12,

Buenos Ayres, junho 1949, p. 6.

29. Idem, ibidem, p. 8-9. Agradeço a Andrea Giunta por esta informação. aos países desenvolvidos. Uma sessão editorial do Cuadernos de critica artística de junho de 1949, por exemplo, agradecia excessivamente à França pelas duas exposições de arte ("From Manet to Today" e a mostra de Degand) por sua grandiosidade:

Quem diz francês, no nosso século, pode estar certo de que se refere ao mais importante da arte universal (...). O público tem correspondido aos esforços. Milhares de espectadores de todas as condições sociais e culturais têm desfilado pelas salas do último andar do Museu Nacional, muitos atraídos pelo prestígio da França, e centenas de visitantes, na maioria atônitos, também têm sentido a atração do mesmo prestígio, com signo diferente, nas salas da instituição (Exposição de Degand) ${ }^{28}$.

Mas na sua abertura, sob pesada reverência, foi feita uma crítica semelhante àquela lançada por críticos de arte de Nova Iorque sobre a exposição francesa no Museu Whitney. Críticos de Buenos Aires queriam mais novidades na arte, queriam ver novas tendências, novas direções além dos velhos caminhos já trilhados e, de certa forma enfraquecidos, do passado de gloria francês. Aqui, a exposição de Degand foi elogiada pela sua ousadia e pela inovação:

Queremos a França e sua arte acima de tudo e todos. Nenhum homem de cultura na América, especialmente no Rio da Prata, deixa de alimentar uma fanática admiração pela cultura francesa (...). O que necessitamos e queremos, portanto, é vibrar em uníssono com os espíritos novos, com os que abrem caminhos, embora esta aspiração não signifique que neguemos os mestres do passado. Somos povos novos e como tal nos fazem falta raízes, mas também pretendemos que nos ajudem a brotar. Nem tudo é semente. É necesario que se regue a terra e que vejamos como são as flores e os frutos nos países mais adiantados que nos servem de exemplo ${ }^{29}$.

Léon Degand teria ficado envergonhado se pudesse ter acesso a esse texto, não só porque, sendo belga, ele estaria defendendo a cultura parisiense, mas também porque ele estava na verdade fazendo o "bom" trabalho de propaganda que as instituições francesas, em seu conservadorismo, eram incapazes de fazer.

Foi, no entanto, um Degand profundamente frustrado e abatido que embrulhou todas as pinturas novamente e as colocou em outro cargueiro em direção à França. $\mathrm{O}$ que começou como um impressionante sonho de invasão cultural, com desejos de produção de algo parecido com o poder do culto à carga, acabou em um triste retorno à base parisiense onde pintores desiludidos que, apesar dos repetidos esforços feitos por Degand no Brasil, não realizaram nenhuma venda durante sua aventura e estavam à espera do crítico para que ele reagrupasse e produzisse uma 
30. Já em 1950, Charles

Estienne escreveu um livro chamado L'art abstrait est-il un académisme? (coleç̃o Le Cavalier d'Epée, Edition de Beaune, Paris).

nova revista de arte chamada Art D'Aujourd'hui, dedicada exclusivamente à defesa da abstração geométrica. Também nesse caso eles não tiveram muita sorte, pois o seu estilo, cheio de otimismo na organização e no racionalismo intelectual, não era capaz de competir com as novas tendências abstratas expressionistas cujo objetivo era articular o pessimismo crescente da cultura do pós-guerra. Degand desapareceu lentamente em segundo plano e morreu esquecido em 1958 após ter publicado, em 1956, um livro chamado Abstraction-Figuration: Langage et signification de la peinture, no qual ele expôs a sua teoria formal sobre a arte abstrata, defendendo até o fim uma abstração geométrica totalmente oprimida pelo sucesso do expressionismo abstrato e da Abstraction Lyrique ${ }^{30}$.

Talvez ele tivesse morrido feliz se soubesse que a sua tão querida abstração voltaria em grande estilo, sacudindo a França, no início dos anos 1960, a partir da América do Sul de todos os lugares. Cruz Diez, Soto, De Marco e todos os artistas da op art usaram a abstração geométrica para dar vida a um mundo chato da arte. Não tenho certeza se a qualidade lúdica do trabalho teria agradado a Degand, mas estou certo de que a invasão de Paris ao revés, quase nos termos de Degand, uma revanche do Novo Continente, teria feito o belga, senão rir, pelo menos sorrir, pensando que o culto à carga da Abstração afinal de contas não naufragou à toa.

Tradução de

Serge Guilbaut é Professor Associado na University of British Columbia, em Vancouver, Canadá. É autor de How New Iorque stole the idea of modern art: abstract expressionism, freedom and the cold war (1983) e Voir, ne pas voir, faut voir: essais sur la perception et la nonperception des ouevres (1994), entre outros livros. 